\title{
Exudative pharyngitis and Corynebacterium pseudodiphtheriticum: A case report and review of the literature
}

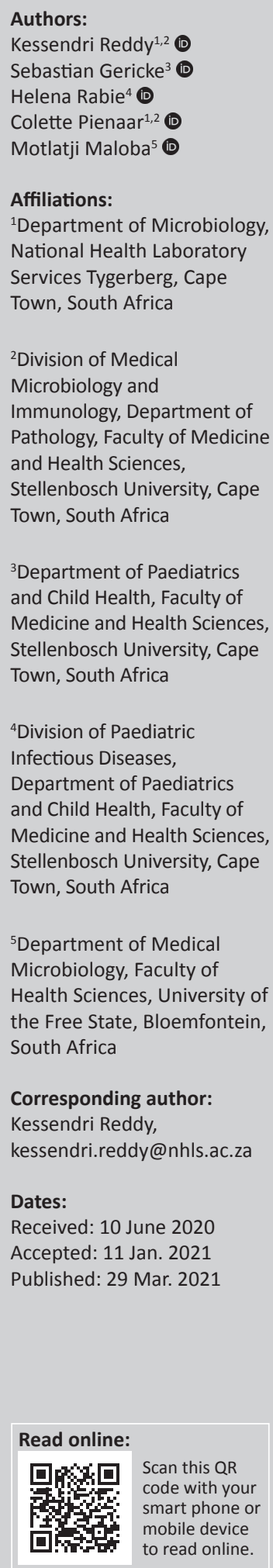

Corresponding author:

Kessendri Reddy,

kessendri.reddy@nhls.ac.za

Dates:

Received: 10 June 2020

Accepted: 11 Jan. 2021

Published: 29 Mar. 2021

Read online:

Scan this QR
code with your
smart phone or
mobile device
to read online.

Corynebacterium pseudodiphtheriticum is an established member of the normal flora of the respiratory tract. This organism is an emerging cause of respiratory tract infection, as well as infection of the skin and skin structures, urinary tract and other sterile sites. The syndrome of C. pseudodiphtheriticum exudative pharyngitis is a diagnostic challenge of particular relevance in recent times as this organism can be confused with Corynebacterium diphtheriae in the clinical setting and in the laboratory. We report a case of exudative pharyngitis, possibly due to C. pseudodiphtheriticum, in a 14-month old, incompletely vaccinated, human immunodeficiency virus (HIV)-positive infant and review the role of this organism in terms of its microbiological profile and identification, disease spectrum and antimicrobial susceptibility pattern.

Keywords: exudative pharyngitis; Corynebacterium pseudodiphtheriticum clinical presentation; Corynebacterium pseudodiphtheriticum laboratory identification; Corynebacterium pseudodiphtheriticum disease spectrum; emerging pathogen.

\section{Background}

Corynebacterium pseudodiphtheriticum has been described as an emerging respiratory pathogen and forms part of normal upper respiratory tract flora. ${ }^{1}$ This organism has been linked to pulmonary disease in patients with underlying lung abnormalities, chronic medical conditions and immunocompromised states, including human immunodeficiency virus (HIV), ${ }^{1,2,3}$ although disease is also described in immunocompetent patients. Respiratory tract disease caused by this organism is likely to be underestimated, given its role as a respiratory tract commensal.

We report a case of exudative pharyngitis potentially caused by C. pseudodiphtheriticum in an unvaccinated HIV-positive infant. There have been a handful of cases describing exudative pharyngitis in conjunction with $C$. pseudodipththeriticum to date; this case provides further evidence of its possible aetiological role and highlights the need for its inclusion in the differential diagnosis of diphtheria. This case is of particular relevance in the current climate of reduced vaccination uptake globally, when clinical acumen surrounding the syndrome of exudative pharyngitis should be maintained.

\section{Clinical case}

\section{Presentation}

A 14-month-old, previously well boy presented to a district hospital in the Western Cape in December 2016 with respiratory distress related to upper airway obstruction. The boy was moderately acutely malnourished and newly diagnosed with HIV on admission.

The child presented with a short history of fever, dysphagia and lethargy. He had a household contact with pulmonary tuberculosis (TB); no TB chemoprophylaxis was given. He had no travel history. Vaccination status was incomplete, with only birth vaccinations administered (Bacille Calmette Guérin [BCG] and oral polio vaccine).

On examination, the child was in shock and had respiratory distress with drooling, forward posturing, grunting and pulsus paradoxus. Oropharyngeal examination revealed an inflamed and oedematous uvula and tonsils with a thick, white, friable membrane adherent to

How to cite this article: Reddy K, GerickeS, Rabie H, Pienaar C, Maloba M. Exudative pharyngitis and Corynebacterium pseudodiphtheriticum A case report and review of the literature. S Afr J Infect Dis. 2021;36(1), a225. https://doi.org/10.4102/sajid.v36i1.225

Copyright: ( 2021 . The Authors. Licensee: AOSIS. This work is licensed under the Creative Commons Attribution License. 
the oropharynx which bled upon touch (Figure 1), prompting a provisional diagnosis of diphtheria.

No neck swelling, cervical lymphadenopathy, cranial nerve palsies or muscle weakness was present. Examination of the chest was not suggestive of lower respiratory tract infection.

Potential aetiological considerations included the following: group A streptococcus (Streptococcus pyogenes), group C or G streptococcus, diphtheria, Arcanobacterium haemolyticum, adenovirus, Epstein-Barr virus (EBV), acute HIV infection and candidiasis.

\section{Management}

Fluid resuscitation, supplemental oxygen and adrenaline nebulisations were provided.

Ceftriaxone (a third-generation cephalosporin) was given intravenously along with paracetamol. The child was

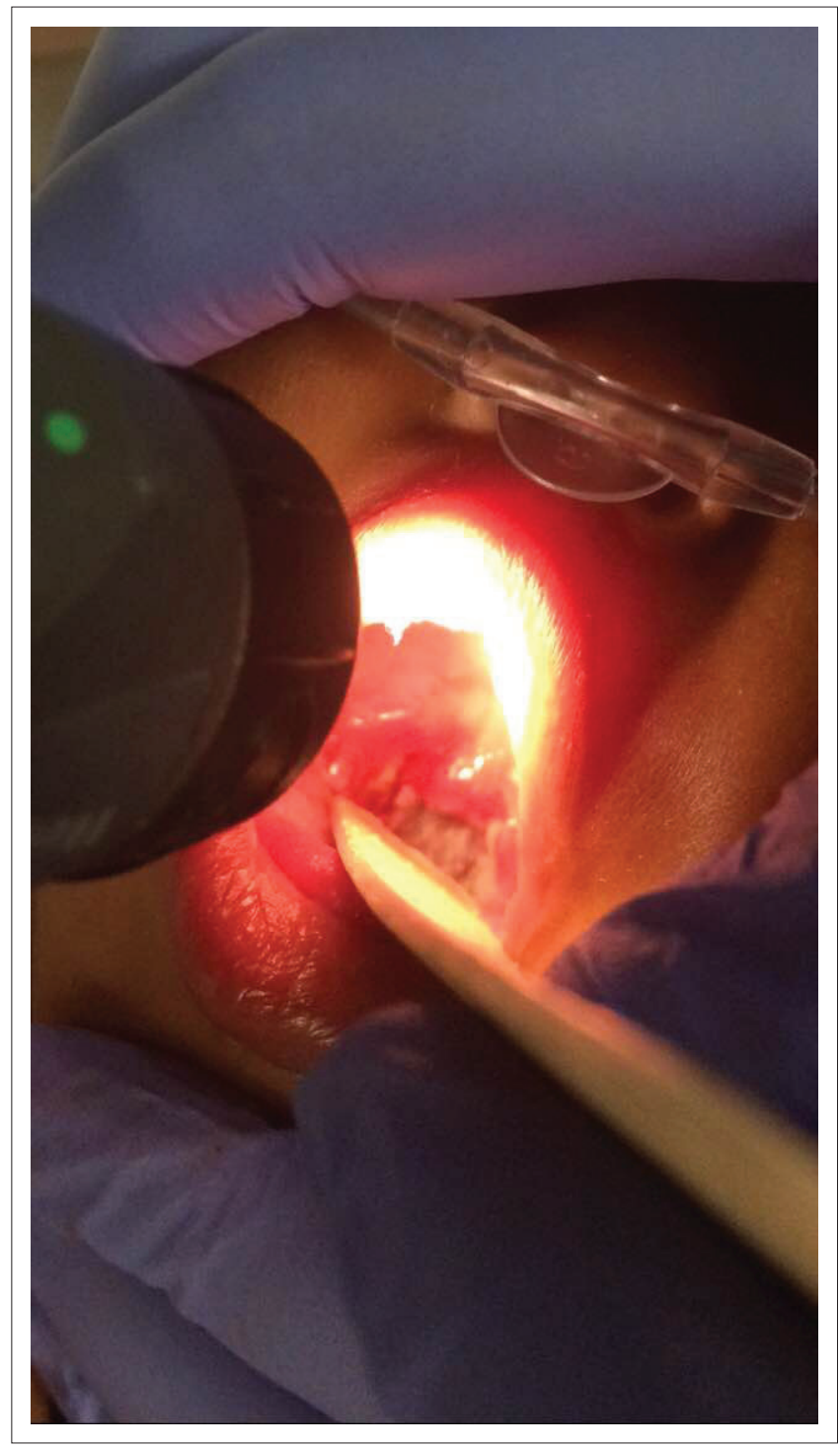

FIGURE 1: White membrane adherent to the pharynx noted on oropharyngea examination on presentation in a 14-month-old incompletely vaccinated infant with respiratory distress. intubated because of worsening respiratory distress and transferred to Tygerberg Hospital's Paediatric Intensive Care Unit. Diphtheria antitoxin could not be sourced, and was omitted from patient management.

Infection control precautions were followed as for diphtheria whilst awaiting confirmatory results. Standard precautions were combined with droplet precautions, including patient isolation, glove and apron use, and the use of facemasks for both the patient and healthcare providers.

\section{Investigations}

His white cell count was $1.4 \times 10^{9} / \mathrm{L}$, haemoglobin $9.0 \mathrm{~g} / \mathrm{dL}$ and platelet count $54 \times 10^{9} / \mathrm{L}$. The serum $\mathrm{C}$-reactive protein (CRP) was $258 \mathrm{mg} / \mathrm{L}$. An HIV-1 antibody test and polymerase chain reaction (PCR) performed on admission were positive. His absolute $\mathrm{CD}_{4}$ (cluster of differentiation 4) count was 356 cells / $\mu \mathrm{L}$ (29\%). An HIV viral load was not performed.

Epstein-Barr virus serology supported previous exposure (EBV nuclear antigen IgG positive, EBV viral capsid antigen IgM negative). Herpes Simplex Virus $1 / 2$ and adenovirus PCR were negative.

Blood cultures revealed no growth.

A tracheal aspirate on admission showed occasional nonbranching small Gram-positive bacilli in Chinese letter formation and no neutrophils on Gram stain, and revealed no growth after $48 \mathrm{~h}$ in a $5 \% \mathrm{CO}_{2}$-enriched incubator. A nasal swab taken on admission showed a pure growth of Corynebacterium colonies. This sample was auramine $\mathrm{O}$ smear-negative for TB and negative on Xpert MTB/Rif testing (Cepheid, Sunnyvale, California).

Two throat swabs taken in the first $24 \mathrm{~h}$ of admission (one prior to antibiotics) showed no pathogens after $72 \mathrm{~h}$ of incubation. The throat swabs and a nasal swab were also cultured and tested molecularly at the National Institute for Communicable Diseases and were culture-negative and PCR-negative for Corynebacterium diphtheriae toxin. No membrane tissue samples were collected.

\section{Outcome and follow-up}

The patient improved steadily on a 14-day course of ceftriaxone. Antiretroviral therapy and catch-up vaccinations ${ }^{4}$ were commenced on discharge.

\section{Public health response}

Nasal and throat swabs were collected from 36 asymptomatic household and healthcare contacts. Corynebacterium pseudodiphtheriticum was isolated from the household contacts only: the index patient's mother and two children in the household (aged 4 and 9 years). These contacts received a 5-day course of azithromycin. 


\section{Laboratory identification of Corynebacterium pseudodiphtheriticum}

Throat and nasal swabs were inoculated onto telluritecontaining and routine media and incubated at $35^{\circ} \mathrm{C}$ in ambient and $5 \% \mathrm{CO}_{2}$-containing incubators, respectively; colony growth was better in the $\mathrm{CO}_{2}$-enriched atmosphere. Grey-black colonies suspicious of $C$. diphtheriae were observed on telluritecontaining media after $48 \mathrm{~h}$ incubation, with corresponding pure growth of white, butyrous colonies on tryptose blood agar on the nasal sample only. Gram stain of these colonies revealed non-branching, uniform Gram-positive bacilli.

Neither beta-haemolytic colonies nor yeasts were cultured from any of the samples.

Biochemical identification with the VITEK(R) 2 ANC system (bioMérieux, Marcy l'Etoile, France) confirmed by the BD BBL Crystal $^{\mathrm{TM}}$ Gram Positive ID Kit (Becton Dickinson and Company, Franklin Lakes, USA), convincingly identified C. pseudodiphtheriticum. Diphtheria toxin was not detected molecularly or phenotypically (in-house PCR negative at the National Institute for Communicable Diseases, Elek test negative).

Limited susceptibility testing was performed using the gradient-diffusion based E-test method (bioMérieux, Marcy l'Etoile, France). Results were interpreted using Corynebacterium species criteria (Clinical and Laboratory Standards Institute M45 document, 2015) and are summarised in Table 1.

\section{Ethical consideration}

Informed consent was obtained from the child's mother and ethical approval was granted by Stellenbosch University's Human Health Research Ethics Committee (Reference number C20/01/002).

\section{Discussion}

Corynebacterium pseudodiphtheriticum is an aerobic non-sporeforming Gram-positive bacillus, forming part of the upper respiratory tract flora. ${ }^{1,2}$ Recent studies have investigated the probiotic role of C. pseudodiphtheriticum in reducing nasal colonisation with Staphylococcus aureus, ${ }^{5,6}$ Streptococcus pneumoniae and respiratory syncytial virus. ${ }^{7}$

Corynebacterium pseudodiphtheriticum has also been associated with respiratory tract infection, including pneumonia, bronchitis and single cases of necrotising tracheitis and a lung abscess. . $^{3,8,9}$

These infections have largely been noted in patients who are immunosuppressed, such as HIV-positive patients or transplant recipients; patients with underlying lung disease, such as chronic obstructive airways disease; and patients with underlying medical conditions, such as congestive cardiac failure, ischaemic heart disease and malignancy. ${ }^{1,2,3,10}$ Patients with cystic fibrosis may be particularly at risk. ${ }^{11}$
Pulmonary infection has also been linked to invasive respiratory procedures such as endotracheal intubation, presumably because of direct introduction of this commensal into the lung. ${ }^{12}$ Recent data suggest that previous exposure to antimicrobials favours colonisation with this organism. ${ }^{1}$ The few cases of lower respiratory tract infection reported in immunocompetent patients suggest that an older age may play a role ${ }^{3,8}$ but this has been challenged. ${ }^{13}$

Co-infection with recognised respiratory tract pathogens has been reported ${ }^{2,3,11,12,13}$ and a co-pathogenic role theorised. ${ }^{10}$ Although carriage of these organisms can result in sample contamination, microbiological methods to determine significance include moderate-to-substantial palisading Grampositive bacilli ${ }^{12}$ or diphtheroids within polymorphonuclear leucocytes on Gram stain, ${ }^{3}$ and substantial growth of diphtheroids on culture, ${ }^{10}$ in conjunction with clinical presentation and underlying risk factors. ${ }^{2}$

Other infectious processes associated with C. pseudodiphtheriticum include infective endocarditis, ${ }^{14,15}{ }^{\text {keratitis, }}{ }^{1}$ endophthalmitis, ${ }^{1}$ skin infection, ${ }^{16}$ urinary tract infection, ${ }^{13}$ osteitis and septic arthritis. ${ }^{13,17,18}$ To our knowledge, three cases of exudative pharyngitis because of C. pseudodiphtheriticum have been reported to date, as summarised in Table 2 .

TABLE 1: Antimicrobial susceptibility testing results of the Corynebacterium pseudodiphtheriticum strain isolated on nasal swab from a 14-month-old infant presenting with exudative pharyngitis.

\begin{tabular}{lcc}
\hline $\begin{array}{l}\text { Antimicrobial agent } \\
\text { tested }\end{array}$ & $\begin{array}{c}\text { Minimum inhibitory } \\
\text { concentration }(\mu \mathrm{g} / \mathrm{mL}) \dagger\end{array}$ & $\begin{array}{c}\text { Interpretation category } \\
\text { for Corynebacterium } \\
\text { species, CLSI }\end{array}$ \\
\hline Penicillin & 0.012 & Susceptible \\
Cefotaxime/Ceftriaxone & 0.047 & Susceptible \\
Ciprofloxacin & 0.094 & Susceptible \\
Vancomycin & 0.19 & Susceptible \\
Azithromycin & 0.125 & - \\
\hline
\end{tabular}

CLSI, Clinical and Laboratory Standards Institute M45 document, 3rd edition 2015.

$\downarrow$, Minimum inhibitory concentration obtained by gradient diffusion testing (Etest, bioMérieux, Marcy l'Etoile, France).

TABLE 2: A summary of important clinical features in reported cases of Corynebacterium pseudodiphtheriticum exudative pharyngitis to date (June 2020).

\begin{tabular}{|c|c|c|c|}
\hline Variable & Case $1-1996 \dagger$ & Case 2-1997 & Case $3-2014 \S$ \\
\hline Age & 32-year old & 4-year old & 6 -year old \\
\hline Gender & Male & Female & Female \\
\hline $\begin{array}{l}\text { Presenting } \\
\text { symptom }\end{array}$ & $\begin{array}{l}\text { Sore throat, } \\
\text { dysphagia, fever }\end{array}$ & $\begin{array}{l}\text { Fever, generalised } \\
\text { lymphadenopathy }\end{array}$ & $\begin{array}{l}\text { Fever, sore throat, } \\
\text { neck swelling, nasal } \\
\text { obstruction, toxic }\end{array}$ \\
\hline Oropharynx & $\begin{array}{l}\text { Greyish-white } \\
\text { exudate from tonsils } \\
\text { to posterior } \\
\text { pharyngeal wall, } \\
\text { enlarged tonsils, } \\
\text { tender cervical } \\
\text { lymphadenopathy, } \\
\text { erythema and } \\
\text { oedema }\end{array}$ & $\begin{array}{l}\text { Greyish-white } \\
\text { membrane attached } \\
\text { to posterior } \\
\text { pharyngeal wall, } \\
\text { erythema }\end{array}$ & $\begin{array}{l}\text { White, leathery } \\
\text { membrane over } \\
\text { tonsils, congestion, } \\
\text { cervical } \\
\text { lymphadenopathy }\end{array}$ \\
\hline Underlying history & Not reported & Not reported & Not reported \\
\hline Treatment & $\begin{array}{l}\text { Penicillin IM, } \\
\text { diphtheria antitoxin }\end{array}$ & $\begin{array}{l}\text { Cefprozil and } \\
\text { erythromycin }\end{array}$ & $\begin{array}{l}\text { Penicillin IV, } \\
\text { diphtheria antitoxin }\end{array}$ \\
\hline Outcome & Cured & Cured & Cured \\
\hline $\begin{array}{l}\text { Immunisation } \\
\text { history }\end{array}$ & $\begin{array}{l}\text { 'All' received in } \\
\text { childhood }\end{array}$ & Not immunised & Fully immunised \\
\hline
\end{tabular}

Note: Please see the full reference list of the article, Reddy K, Gericke S, Rabie H, Pienaar C, Maloba M. Exudative pharyngitis and Corynebacterium pseudodiphtheriticum: A case report and review of the literature. S Afr J Infect Dis. 2021;36(1), a225. https://doi.org/10.4102/ sajid.v36i1.225, for more information.

IM, intramuscular; IV, intravenous.

$\dagger$, Santos et al. ${ }^{19} ; \ddagger$, Izurieta et al. ${ }^{20} ; \S$, Indumathi et al. ${ }^{21}$ 
Despite the fact that C. pseudodiphtheriticum has traditionally been described as non-toxigenic, ${ }^{22}$ we believe confirmation of this is advisable in view of the mechanism of transmission of diphtheria toxin. Diphtheria toxin is carried on a $\beta$-phage that infects bacterial cells belonging to the species, C. diphtheriae, C. ulcerans and C. pseudotuberculosis. Clinical experience suggests that this toxin does not affect other Corynebacterium species, although this is not impossible.

The identification of Corynebacterium species can prove complex, adding to the laboratory's diagnostic dilemma. ${ }^{23}$ The gold standard for laboratory identification is sequencing of the hypervariable $r p o B$ gene, which is not routinely available. Sequencing of the $16 \mathrm{~S}$ ribosomal RNA gene is more widely available but may be inferior to partial $r p o B$ sequencing, ${ }^{24}$ although database updates may have addressed this.

Common, presently available biochemical/proteomic methods to identify C. pseudodiphtheriticum in South Africa include:

- VITEK $^{\circledR} 2$ ANC (bioMérieux, Marcy l’Etoile, France): C. pseudodiphtheriticum correctly identified in nine isolates identified on $16 \mathrm{~S}$ rRNA sequencing. ${ }^{25}$

- BD BBL Crystal ${ }^{\mathrm{TM}}$ Gram Positive ID (Becton Dickinson and Company, Franklin Lakes, USA): Correctly identified 7 of 12 control Corynebacterium isolates to species level, misidentified one Corynebacterium species as C. pseudodiptheriticum. ${ }^{26}$

- $\mathrm{API}^{\circledR}$ Coryne version 4.0 (bioMérieux, Marcy l'Etoile, France): Correctly identified one control strain as C. pseudodiphtheriticum ${ }^{26}$ and overall correct identification in $97.7 \%$ of the 1880 Corynebacterium species tested. ${ }^{27}$

- Vitek MS (bioMérieux, Marcy l’Etoile, France): 77\% of 114 Corynebacterium isolates with species-level identification correctly identified, including one C. pseudodiphtheriticum strain. $^{28}$

Corynebacterium pseudodiphtheriticum is usually susceptible to penicillin, vancomycin, rifampicinand theaminoglycosides, ${ }^{2,29}$ but geographical variability may be marked. A recently published study from Canada reported C. pseudodiphtheriticum/C. propinquum as displaying the lowest minimum inhibitory concentration (MIC) to penicillin. ${ }^{29}$ In contrast, penicillin resistance was reported in $38.9 \%-44.2 \%$ of C. pseudodiphtheriticum strains from a variety of anatomical sites in Brazil in 2009; $15.0 \%$ of these strains were multidrug-resistant (resistant to more than 10 antimicrobial agents). ${ }^{13}$ In general, Corynebacterium species other than $C$. diphtheriae have become less susceptible to the beta-lactams in the last two decades. ${ }^{29}$ In this patient, de-escalation from ceftriaxone to penicillin was not possible because of a shortage of penicillin.

Macrolide and lincosamide resistance occurs consistently, 1,2,10,12,29,30 which is concerning as erythromycin and azithromycin are recognised alternative options in the management of the clinical syndrome of diphtheria. ${ }^{31}$ Quinolone and trimethoprim-sulphamethoxazole resistance is variable..$^{3,8,13,29}$ Susceptibility rates to tetracycine, linezolid and daptomycin are high. ${ }^{29}$ In this case, the low azithromycin MIC was reassuring for the prophylactic use of this agent in the carriers identified, although the clinical significance of carriage in this context is uncertain.

The limitations of this case study include the isolation of this organism from only a single admission nasal swab with a suggestive but unproven causative link and the absence of comprehensive antibiotic susceptibility testing. We did not assess strain relatedness between isolates, although the absence of this organism from any other contacts screened increases the likelihood of these being genetically related. The production of a novel toxin producing similar effects to diphtheria toxin was not explored and could be researched in future studies.

\section{Conclusion}

This case adds evidence to the likely role of $C$. pseudodiphtheriticum as an emerging pathogen and highlights diagnostic dilemmasfaced both clinically and microbiologically. The direct causal link was not present, but the absence of an alternative explanation for the clinical syndrome lends more weight to the possible aetiological role of this organism in exudative pharyngitis. Local susceptibility data are needed, as are further reports exploring the significance of isolation of this organism in a South African setting with our high prevalence of HIV infection. It is important that this organism is considered in the workup of exudative pharyngitis although, until its role is clarified, emphasis should remain on excluding diphtheria in the current climate of suboptimal vaccination coverage and anti-vaccination sentiment.

\section{Acknowledgements}

The authors wish to thank the staff at the National Health Laboratory Services (NHLS) Tygerberg, the National Institute for Communicable Diseases' Centre for Respiratory Diseases and Meningitis, and Mr Valentino Horne (NHLS Greenpoint) for their assistance with the laboratory testing of this isolate. We would like to acknowledge Professors Lucille Blumberg and Anne von Gottberg, Sister Marina Aucamp and the Western Cape Provincial Communicable Disease Coordination team for their advice and support. The patients and the dedicated staff at Tygerberg Hospital's Department of Paediatrics made this research possible.

\section{Competing interests}

The authors declare that they have no financial or personal relationships that may have inappropriately influenced them in writing this case report.

\section{Authors' contributions}

K.R. conceptualised the study and formulated the manuscript. S.G. and H.R. completed the clinical presentation component. C.P. and M.M. critically reviewed the manuscript. 


\section{Funding information}

This research received no specific grant from any funding agency in the public, commercial or not-for-profit sectors.

\section{Data availability}

Data sharing is not applicable to this article as no new data were created or analysed in this study.

\section{Disclaimer}

The views and opinions expressed in this article are those of the authors and do not necessarily reflect the official policy of any affiliated agency of the authors.

\section{References}

1. Burkovski A. Corynebacterium pseudodiphtheriticum: Putative probiotic, opportunistic infector, emerging pathogen. Virulence. 2015;6(7):673-674. https://doi.org/10.1080/21505594.2015.1067747

2. Van Roeden SE, Thijsen SF, Sankatsing SUC, Limonard GJM. Clinical relevance of Corynebacterium pseudodiphtheriticum in lower respiratory tract specimens. Infect Dis. 2015;47(12):862-868. https://doi.org/10.3109/23744235.2015.1070962

3. Manzella JP, Kellogg JA, Parsey KS. Corynebacterium pseudodiphtheriticum: A respiratory tract pathogen in adults. Clin Infect Dis. 1995;20(1):37-40. https://doi. org/10.1093/clinids/20.1.37

4. The National Department of Health. Vaccinator's manual: 'Immunisation that works'. Expanded programme on Immunisation in South Africa (EPI-SA). Pretoria: National Department of Health; 2012.

5. Kiryukhina NV, Melnikov VG, Suvorov AV, Morozova YA, Ilyin VK. Use of Corynebacterium pseudodiphtheriticum for elimination of Staphylococcus aureus
from the nasal cavity in volunteers exposed to abnormal microclimate and altered from the nasal cavity in volunteers exposed to abnormal microclimate and altered
gaseous environment. Probiotics Antimicrob Proteins. 2013;5(4):233-238. https://doi.org/10.1007/s12602-013-9147-x

6. Hardy BL, Dickey SW, Plaut RD, et al. Corynebacterium pseudodiphtheriticum exploits Staphylococcus aureus virulence components in a novel polymicrobial defense strategy. mBio. 2019;10(1):1-24. https://doi.org/10.1128/mBio.02491-18

7. Kanmani $\mathrm{P}$, Clua $\mathrm{P}$, Vizoso-Pinto $\mathrm{MG}$, et al. Respiratory commensal bacteria Corynebacterium pseudodiphtheriticum improves resistance of infant mice to respiratory syncytial virus and Streptococcus pneumoniae superinfection. Front respiratory syncytial virus and Streptococcus pneumoniae superinfect
Microbiol. 2017;8:1-14. https://doi.org/10.3389/fmicb.2017.01613

8. Ahmed K, Kawakami K, Watanabe K, Mitsushima H, Nagatake T, Matsumoto K. Corynebacterium pseudodiphtheriticum: A respiratory tract pathogen. Clin Infect Dis. 1995;20(1):41-46. https://doi.org/10.1093/clinids/20.1.41

9. Colt HG, Morris JF, Marston BJ, Sewell DL. Necrotizing tracheitis caused by Corynebacterium pseudodiphtheriticum: Unique case and review. Rev Infect Dis. 1991;13(1):73-76. https://doi.org/10.1093/clinids/13.1.73

10. Gutierrez-Rodero F, Ortiz de la Tabla V, Martinez C, et al. Corynebacterium pseudodiphtheriticum: An easily missed respiratory pathogen in HIV-infected patients. Diagn Microbiol Infect Dis. 1999;33(4):209-216. https://doi. org/10.1016/S0732-8893(98)00163-1

11. Bittar F, Cassagne C, Bosdure E, et al. Outbreak of corynebacterium pseudodiphtheriticum infection in cystic fibrosis patients, France. Emerg Infect Dis. 2010;16(8):1231-1236. https://doi.org/10.3201/eid1608.100193

12. Nhan TX, Parienti JJ, Badiou G, Leclercq R, Cattoir V. Microbiological investigation and clinical significance of Corynebacterium spp. in respiratory specimens. Diagn Microbiol Infect Dis. 2012;74(3):236-241. https://doi.org/10.1016/j. diagmicrobio.2012.07.001
13. Camello TCF, Souza MC, Martins CAS, et al. Corynebacterium pseudodiphtheriticum isolated from relevant clinical sites of infection: A human pathogen overlooked in emerging countries. Lett Appl Microbiol. 2009;48(4):458-464. https://doi. emerging countries. Lett Appl Microbi
org/10.1111/j.1472-765X.2009.02553.x

14. Morris A, Guild I. Endocarditis due to Corynebacterium pseudodiphtheriticum: Five case reports, review, and antibiotic susceptibilities of nine strains. Rev Infect Dis. 1991;13(5):887-892. https://doi.org/10.1093/clinids/13.5.887

15. Wilson ME, Shapiro DS. Native valve endocarditis due to Corynebacterium pseudodiphtheriticum. Clin Infect Dis. 1992;15(6):1059-1060. https://doi. org/10.1093/clind/15.6.1059

16. Hemsley C, Abraham S, Rowland-Jones S. Corynebacterium pseudodiphtheriticum - A skin pathogen Corynebacterium. Clin Infect Dis. 1999;(29):939-940. https:// doi.org/10.1086/520466

17. Erturan G, Holme H, lyer S. Corynebacterium pseudodiphtheriticum septic arthritis secondary to intra-articular injection - A case report and literature review. J Med Microbiol. 2012;61(6):860-863. https://doi.org/10.1099/ jmm.0.037937-0

18. Kemp M, Holtz K, Andresen K, Christensen JJ. Demonstration by PCR and DNA sequencing of Corynebacterium pseudodiphtheriticum as a cause of joint infection and isolation of the same organism from a surface swab specimen from the patient. J Med Microbiol. 2005;54(7):689-691. https://doi.org/10.1099/ jmm.0.45954-0

19. Santos MR, Gandhi S, Vogler M, Hanna BA, Holzman RS. Suspected diphtheria in an Uzbek National: Isolation of Corynebacterium pseudodiphtheriticum resulted in a false-positive presumptive diagnosis. Clin Infect Dis. 1996;22(4):735. https:// doi.org/10.1093/clinids/22.4.735

20. Izurieta HS, Strebel PM, Youngblood T, Hollis DG, Popovic T. Exudative pharyngitis possibly due to Corynebacterium pseudodiphtheriticum, a new challenge in the differential diagnosis of diphtheria. Emerg Infect Dis. 1997;3(1):65-68. https:// differential diagnosis of diphtheria.
doi.org/10.3201/eid0301.970109

21. Indumathi V, Shikha R, Suryaprakash D. Diphtheria-like illness in a fully immunised child caused by Corynebacterium pseudodiphtheriticum. Indian J Med Microbiol. 2014;32(4):443-445. https://doi.org/10.4103/0255-0857.142250

22. Lipsky BA, Goldberger AC, Tompkins LS, Plorde JJ. Infections caused by nondiphtheria Corynebacteria. Rev Infect Dis. 1982;4(6):1220-1235. https://doi. org/10.1093/clinids/4.6.1220

23. Zasada A, Mosiej E. Contemporary microbiology and identification of Corynebacteria spp. causing infections in human. Lett Appl Microbiol. 2018;66(6):472-483. https://doi.org/10.1111/lam.12883

24. Khamis A, Raoult D, La Scola B. Comparison between rpoB and $16 S$ rRNA gene sequencing for molecular identification of 168 clinical isolates of Corynebacterium. J Clin Microbiol. 2005;43(4):1934-1936. https://doi.org/10.1128/JCM.43.4.19341936.2005

25. Rennie RP, Brosnikoff C, Turnbull L, et al. Multicenter evaluation of the Vitek 2 anaerobe and Corynebacterium identification card. J Clin Microbiol. 2008;46(8):2646-2651. https://doi.org/10.1128/JCM.00449-08

26. Adderson EE, Boudreaux JW, Cummings JR, et al. Identification of clinical coryneform bacterial isolates: Comparison of biochemical methods and sequence analysis of 16S rRNA and rpoB genes. J Clin Microbiol. 2008;46(3):921-927. https://doi.org/10.1128/JCM.01849-07

27. Marcy-l'Etoile F, SA B. API ${ }^{\circledR}$ Coryne version 4.0 [package insert]. Marcy l'Etoile, France: bioMérieux; 2009.

28. Navas M, Pincus DH, Wilkey K, et al. Identification of aerobic gram-positive bacilli by use of Vitek MS. J Clin Microbiol. 2014;52(4):1274-1277. https://doi. org/10.1128/JCM.03483-13

29. Neemuchwala A, Soares D, Ravirajan V, Marchand-austin A, Kus JV, Patel SN. In vitro antibiotic susceptibility pattern of non-diphtheriae Corynebacterium isolates in Ontario, Canada, from 2011 to 2016. Antimicrob Agents Chemother. 2018;62(4):1-9. https://doi.org/10.1128/AAC.01776-17

30. Díez-Aguilar M, Ruiz-Garbajosa P, Fernández-Olmos A, et al. Non-diphtheriae Corynebacterium species: An emerging respiratory pathogen. Eur J Clin Microbio Infect Dis. 2013;32(6):769-772. https://doi.org/10.1007/s10096-012-1805-5

31. Archary M, Cohen C, De Gouveia L, et al. Diphtheria: NICD recommendations for diagnosis, management and public health response [homepage on the Internet]. Johannesburg; 2018 [cited 2018 Dec 12]. Available from: https://www.nicd.ac.za/ wp-content/uploads/2017/03/NICD-guidelines_diphtheria_v3_28-May-2018.pdf 